\title{
NON-MEDICAL MANAGEMENT OF SPINAL CORD INJURY
}

\author{
By DAVID BARRIE ${ }^{1}$ \\ Liberty Mutual Insurance Company, Scituate, Massachusetts (U.S.A.)
}

SURvival of spinal cord injured persons in large numbers is a relatively recent medical development, having had its inception during the past quarter century. During these years, much has been learned and practised to the great benefit of paraplegic citizens, worldwide. Historically, the medical management of these cases has probably been the responsibility of physicians. The purpose of this paper is to demonstrate that these patients require much more than expert medical care in qualified facilities.

When optimum medical recovery has taken place and the stabilised patient is wheeled out of the hospital door, many almost insuperable problems are presented to him.

First and foremost is economic survival of the paraplegic and his family. Many countries have different approaches and solutions to this major barrier to normality. In the United States there may be as many as Io different agencies, types of private insurance, public benefits and employment benefits available, but, some patients are not qualified by status or circumstances of injury to adequate benefits. Frequently they lack the sophistication required to locate, identify and deal with public and private bureaucracy. They need experienced help to find their way through these inexcusable labyrinths.

Without suitable and, accessible housing, they may have to be institutionalised indefinitely or become almost literal prisoners in an unsuitable residence. The location and modification of suitable housing within their needs and meeting their ability to pay is essential. Again, they require help to avoid discouraging physical and financial conditions. Standards needed for wheelchair housing are maximum efficiency at the lowest cost.

Mobility is greatly prized by all of us, but by none more than the wheelchair citizen. This means a proper motorised means of transportation must be acquired, licenced and maintained. In the United States, almost Ioo per cent. of paraplegics and many quadriplegics use conventional stock motor vehicles with simple, inexpensive hand controls. They have been, or should have been, taught transfer wheelchair handling in and out of cars, and trained sufficiently to obtain a licence. It must also be planned properly for them to get in and out of their vehicles at home in such circumstances as to allow easy egress and ingress from and to the building. Arrangements for obtaining necessary medications at reasonable prices and in quantity, should be made.

A local physician who will assume enough responsibility to care for the patient's emergency needs and hospital admission, when required, is an essential factor in a successful continuing programme of maximum rehabilitation. The patient's right to return to the spinal cord injury centre when indicated should be assured without official delay.

But of what value will all of the foregoing be if the individual goes home to sit,

${ }^{1}$ Present Address: I62 Branch Street, Scituate, Mass. (U.S.A.). 
brood, wrangle with his family, drink, become obese, give up his hard-won mobility and self-sufficiency, and end up as a total liability to everyone involved?

Most humans are, at birth, provided with sufficient drive, desire, competitiveness and dreams to make them reasonably functional and productive for their working life. The paraplegic finds himself not only robbed of his physical ability, but also in a frequently unequal battle in the competitive labour market. $\mathrm{He}$ is confronted by the able-bodied and by architectural barriers. His old skills may now be valueless. If he is to again become a productive person and regain his status at home aptitude, intelligence and occupational preference testing is required. From such testing, hopefully a course of endeavour suitable for him and of sufficient probability of success will emerge to warrant the necessary investment of public or private funds for a retraining programme. This phase of reintegration of the spinal cord injured is among the most difficult and requires experienced and skilled direction.

Presuming the success of the retraining process, the next thing to do is find a job, with an employer willing to hire a person in a wheelchair and, whose premises are reasonably accessible and include a parking spot for the patient's car. This again is difficult for the paraplegic and his family to accomplish unaided. There is an understandable natural reluctance by most employers to assume the problems of a wheelchair employee when there is ample suitable, and able-bodied help available.

Insurance requirements may present real or imagined obstacles. Adaptation of the physical environment may be difficult or expensive. And finally, it is much easier to hire a disabled person in a wheelchair than to discharge him-to the uninformed public, Scrooge would be a benign benefactor compared to an employer who fired a wheelchair employee!

None of us would feel our lives were purposeful or fulfilled if we did not participate in community, political, social and cultural life. This is equally true for the paraplegic. But so frequently he is automatically excluded by unknowing or unthinking fellows; the activity may not be physically accessible, or encouragement is needed to voluntary participate.

With many paraplegics being young males, the opportunity to participate in appropriate competitive sport is essential. This has been so well demonstrated by Stoke Mandeville and the annual competitive games and innumerable sportengaged wheelchair groups in most countries of the world.

Finally, many paraplegics will profit from counselling and problem-solving throughout their lives. There should be one person to whom they can turn to by letter, phone or, in person for general assistance in all the foregoing areas. It will be recognised that there are many patients who will succeed in spite of our help, and not because of it. These people would succeed whether able or disabled, but they are in the minority. Most spinal cord injury victims need a great deal of help. It is not suggested that they be made dependent on their case manager, but that he be available for consultation, planning and counsel throughout their lives, to the extent necessary.

The author's programme for Liberty Mutual Insurance Company, the largest insurer of industrially injured in the United States, is based on a case manager system; an experienced lay person who coordinates and helps plan and implement a complete programme for every patient. He or she works with every discipline, person and agency involved in the patient's restoration and reintegration to home, work and society. The programme has been tremendously successful, in 
terms of human needs fulfilled and large financial savings. Unfortunately, this approach is available only to a limited number of paraplegics. For years the author has been pleading throughout the United States that the magnitude of the needs of paraplegics demands that government and the public assume the financial cost and case management of these devastating injuries.

Finally I would like to say that the real value of this programme is in lives salvaged, restored and made tolerable and useful to hundreds of courageous men and women. 